\title{
Aging Does Not Affect Beta Modulation during Reaching Movements
}

\author{
Serena Ricci $\left(\mathbb{D},{ }^{1,2}\right.$ Ramtin Mehraram, ${ }^{1,3}$ Elisa Tatti, ${ }^{1}$ Aaron B. Nelson, ${ }^{1}$ \\ Martina Bossini-Baroggi, ${ }^{2}$ Priya Panday, ${ }^{1}$ Nancy Lin, ${ }^{1}$ and M. Felice Ghilardi ${ }^{1}{ }^{1}$ \\ ${ }^{1}$ CUNY Medical School, New York, NY 10031, USA \\ ${ }^{2}$ DIBRIS University of Genoa, 16145, Italy \\ ${ }^{3}$ Institute of Neuroscience, Newcastle University, NE17RU, UK
}

Correspondence should be addressed to Serena Ricci; ricci_serena@ymail.com and M. Felice Ghilardi; lice.mg79@gmail.com

Received 1 February 2019; Revised 9 April 2019; Accepted 17 April 2019; Published 15 May 2019

Guest Editor: Giovanni Pellegrino

Copyright (c) 2019 Serena Ricci et al. This is an open access article distributed under the Creative Commons Attribution License, which permits unrestricted use, distribution, and reproduction in any medium, provided the original work is properly cited.

\begin{abstract}
During movement, modulation of beta power occurs over the sensorimotor areas, with a decrease just before its start (event-related desynchronization, ERD) and a rebound after its end (event-related synchronization, ERS). We have recently found that the depth of ERD-to-ERS modulation increases during practice in a reaching task and the following day decreases to baseline levels. Importantly, the magnitude of the beta modulation increase during practice is highly correlated with the retention of motor skill tested the following day. Together with other evidence, this suggests that the increase of practice-related modulation depth may be the expression of sensorimotor cortex's plasticity. Here, we determine whether the practice-related increase of beta modulation depth is equally present in a group of younger and a group of older subjects during the performance of a 30-minute block of reaching movements. We focused our analyses on two regions of interest (ROIs): the left sensorimotor and the frontal region. Performance indices were significantly different in the two groups, with the movements of older subjects being slower and less accurate. Importantly, both groups presented a similar increase of the practice-related beta modulation depth in both ROIs in the course of the task. Peak latency analysis revealed a progressive delay of the ERS peak that correlated with the total movement time. Altogether, these findings support the notion that the depth of beta modulation in a reaching movement task does not depend on age and confirm previous findings that only ERS peak latency but not ERS magnitude is related to performance indices.
\end{abstract}

\section{Introduction}

Movement is associated with changes of the electroencephalographic (EEG) activity in the beta frequency range from 15 to $30 \mathrm{~Hz}$ recorded mainly over the sensorimotor cortex. During movement planning, beta power decreases reaching a minimum at the end of the movement, event-related desynchronization (ERD) [1]. After the movement, beta power shows a rebound, defined as event-related synchronization (ERS) [2]. Likely, ERD reflects the increased excitability of the motor cortex and the deactivation of somatosensory areas. ERS, instead, may represent the reactivation of the somatosensory area following the motor activity $[3,4]$. There is no clear evidence as to whether ERD and ERS characteristics are related to specific movement attributes [5-7] or whether they change with aging or neurodegenerative processes [8-10]. Interestingly, we have recently found that during practice in a reaching task, ERS magnitude increases $[11,12]$, independently of possible changes in mean power. Such practice-related increases are also evident in the beta modulation depth, computed as the ERS-ERD peak-to-peak difference. Importantly, we have also found that beta modulation decreased to baseline levels twenty-four hours later and that the magnitude of its increase during practice was correlated with retention of motor skill tested the following day [10]. Thus, we interpreted the beta modulation changes occurring during practice as reflecting plasticity-related phenomena: indeed, human and animal studies have shown that beta power increases in parallel with a reduction of cortical excitability and with an increase of GABA levels $[13,14]$. In 
this context, the recurring activation and inactivation of the sensory and motor areas during our task with repetitive reaching movements may be an appropriate scenario to trigger long-term potentiation- (LTP-) related phenomena and may result in an increase of beta modulation depth. In turn, such an increase may reflect a progressive saturation of the mechanisms related to LTP-like plasticity. This idea is supported by work in animal and humans. In particular, high beta power likely reflects high GABA levels [14-20], thus linking increases in beta power to increases of inhibitory processes as well as to decreases of cortical excitability and LTP-related processes. Furthermore, theta burst TMS protocols that modulate local plasticity also induce local changes not only in cortical excitability but also in beta power [13, 21, 22]. Finally, in Parkinson's disease (PD), which is characterized by alterations in the beta frequency range [23-25] and impaired plasticity [26-31], we did not find either the practice-related increases of beta power or the retention of motor improvement that was present in normal subjects. As neural plasticity declines with increasing age [32], it is possible that practice-related beta modulation would also be affected by aging. However, studies on either beta oscillatory activity or plasticity of the sensorimotor cortex report controversial results. For instance, a recent work with a motor sequence task reported increased ERD amplitude over the contralateral sensorimotor area in older (aged from 54 to 75 years) compared to younger adults (aged from 20 to 42 years) [8]. In contrast, another study with a grip task [19] showed a lack of correlation between age and movement-related beta ERD in the contralateral motor area. Similarly, the studies testing LTP-like plasticity of the sensorimotor cortex with paired-associative stimulation (PAS) protocols yielded contrasting results [33-35].

In the present study, we ascertain in a group of younger and older adults whether healthy aging affects practicerelated changes both in terms of magnitude and peak latency of ERD and ERS during a reaching task with the right hand. We focused on the left sensorimotor cortex and on a frontal region that, in previous studies, showed robust beta modulation $[11,12]$.

\section{Materials and Methods}

2.1. Subjects. We tested two groups of subjects: a younger group, with thirteen subjects (mean age \pm SD: $24.2 \pm 4.5$ years, ten women) and an older group with thirteen subjects (mean age \pm SD: $57.5 \pm 8.2$ years, six women). All subjects were right-handed, as determined by the Edinburgh inventory [36], and had no history of neurological or psychiatric disorders. Experiments were conducted with the approval of our Institutional Review Board, and written informed consent was obtained from all participants.

2.2. Experimental Design and Motor Task. All experiments were run in the morning. Subjects were fitted with highdensity 256-electrode EEG cap. The two groups of subjects performed a reaching task (MOT) for 30 minutes. Specifically, as described in previous papers $[37,38]$, subjects were seated in front of a computer screen and moved a hand- held cursor on a digitizing tablet with their right upper limb that was hidden by an opaque surface (Figure $1(\mathrm{a})$ ). On the screen, an array of eight targets $(1 \mathrm{~cm}$ diameter circles) that was equidistant $(4 \mathrm{~cm})$ from a central starting point was present at all times together with the position of the cursor. One of the eight targets blackened with a $1.5 \mathrm{~s}$ interval for $400 \mathrm{~ms}$ in a random order; subjects were instructed to move as soon as possible, minimizing reaction time but avoiding anticipation or guessing, to make overlapping out-andback movements without corrections or stops with sharp reversal within the target (Figure 1(b)). Before the first testing session, all subjects were trained in this task to reach a hit rate of at least $95 \%$.

The session encompassed a total of 840 target presentations divided into 15 sets of 56 each. Between two consecutive sets, subjects paused for an average of 30 seconds.

For each movement, we computed the following: reaction time, defined as the time from the target appearance to the movement onset; total movement time, defined as the time from movement onset to the end of the out and back stroke; peak velocity; and hand-path area, a measure that reflects interjoint coordination, computed as the area included in the trajectory normalized by path length squared (Figure 1(b)). For each subject, we discarded outlier movements that met one of the following criteria: reaction time exceeding $2 \mathrm{SD}$ from the subject's mean, directional error greater than $22^{\circ}$, and movement end less than $100 \mathrm{~ms}$ before the presentation of the next target.

\section{3. $E E G$}

2.3.1. EEG Recording. A high-density EEG was recorded from 256 electrodes (HydroCel net, Electrical Geodesics Inc.) for the entire duration of the experiment with a sampling rate of $250 \mathrm{~Hz}$, using the high impedance amplifier Net Amp 300 and Net Station 4.3. Impedances were kept below 30 $\mathrm{k} \Omega$, and the signal was referenced to the vertex $\mathrm{Cz}$.

2.3.2. EEG Data Preprocessing. Data were preprocessed using the public Matlab toolbox EEGLAB [39]. The continuous EEG signal was filtered with a passband two-way leastsquare FIR filter between 1 and $80 \mathrm{~Hz}$ and a notch filter centered at $60 \mathrm{~Hz}$. Then, signal was divided into 4 -second epochs, centered at the stimulus onset ( -1 to 3 seconds). Also, recordings were visually inspected to define artefactual epochs and channels. Channels affected by bad scalpelectrode contact were replaced with spherical spline interpolation, and artefactual epochs were removed from the recording. Stereotypical artifacts, such as blinks, eye movements, and motion-related signals, were removed with Independent Component Analysis (ICA) with Principal Component Analysis- (PCA-) based dimension reduction [40]. Briefly, we visually inspected the power spectral density, topographical maps, and time activations of each estimated component. The components identified as "artefactual" were removed from the raw EEG signal. Finally, the signal was averaged referenced to proceed with the analyses and reduced to 180 channels, removing 76 channels located on the cheeks and the neck. 
(a)

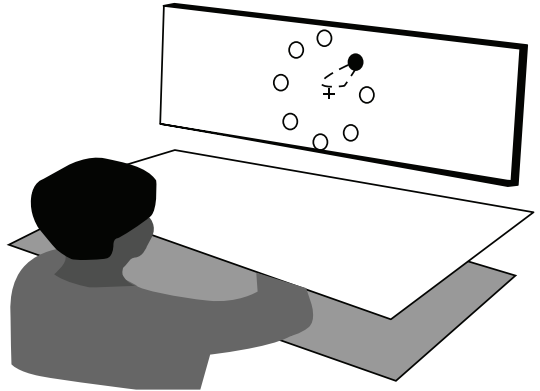

(c)

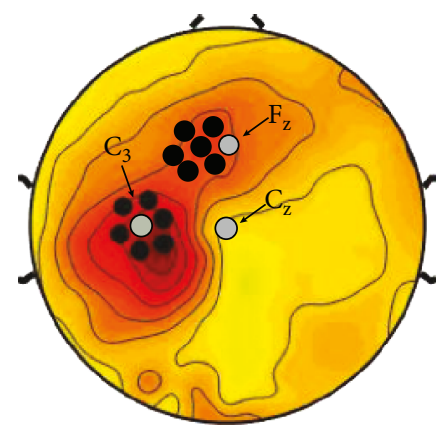

(b)

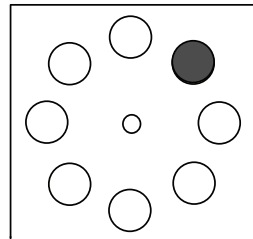

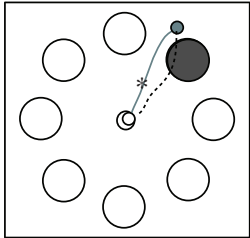

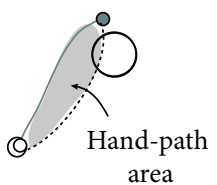

(d)

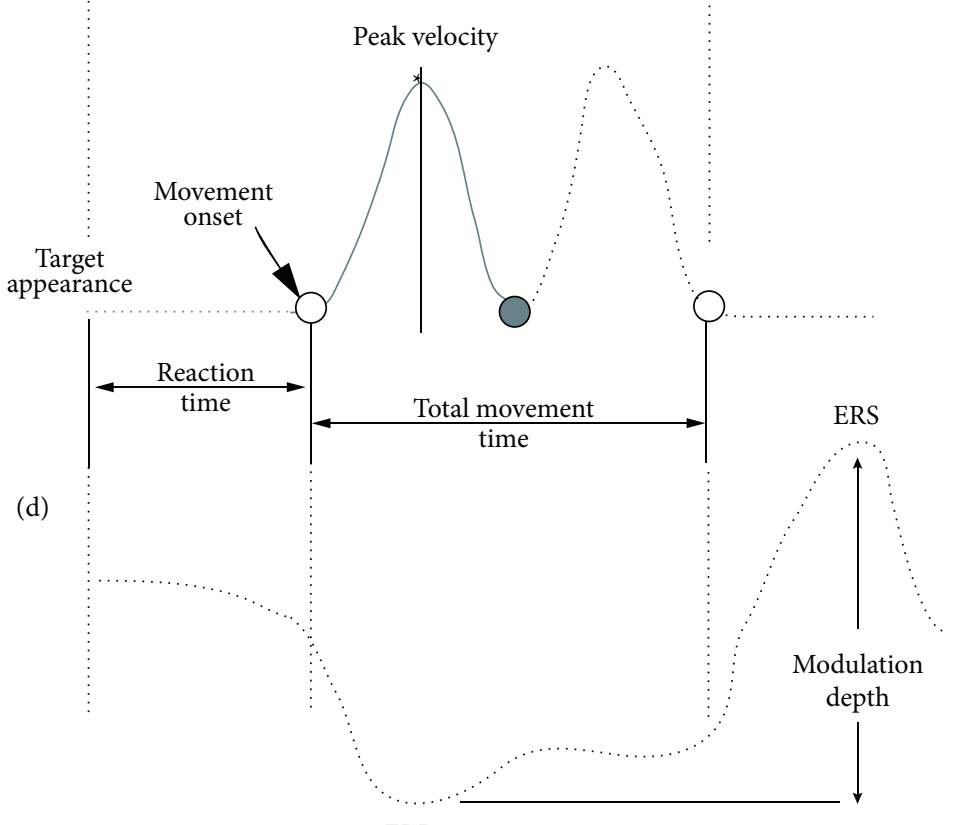

ERD

FIGURE 1: Experimental design and kinematic measures. (a) Testing set up. (b) Upper line: target display on the screen with the appearance of the target (left); the hand-path display during the movement (center); in grey, the hand-path area (left). Bottom line: temporal profile of trajectory velocity with the kinematic parameters used in the analyses. (c) Definition of the regions of interest (ROIs): the left and the frontal ROIs (black dots) with $\mathrm{Cz}, \mathrm{Fz}$, and C3 (grey dots). (d) Representation of beta power changes related to target appearance, movement onset, and end. The peak of event-related desynchronization (ERD) is followed by a rebound (or event-related synchronization, ERS) after the movement end. Beta modulation is defined as the difference between ERD and ERS power.

2.3.3. EEG Data Analyses. As a first step, we aligned each valid trial (i.e., trials that were not discarded from either EEG or kinematic preprocessing) to the time of movement onset; then, we computed time-frequency representations in the 15 to $30 \mathrm{~Hz}$ range $(0.25 \mathrm{~Hz}$ steps), using a short-time Fourier transform approach (Hanning taper, time step-size of 20 $\mathrm{ms}, 5$ cycles adaptive window width). Beta power of each trial and region of interest (ROI) was normalized using the average beta power value computed over the entire motor session as such: $\sum_{i}^{i=1 \text { trials }}(($ BetaEEG $i-$ TotPower $) /$ TotPower $)$, with TotPower defined as the total beta power across all the trials. First, we ascertained whether the two groups of subjects had a comparable beta power in both ROIs with nonparametric permutation testing with false discovery rate correction. Then, we determined the amplitudes of ERD and ERS: ERD amplitude was defined as the minimum value of beta power within an interval between $200 \mathrm{~ms}$ before movement onset to $700 \mathrm{~ms}$ after it; ERS amplitude was the maximum value in the interval from 500 to 1500 ms. Beta modulation depth was computed as the difference between ERS and ERD. We then averaged the data of all the subjects to define two ROIs centered where beta modulation was maximal. Specifically, we defined a left sensorimotor ROI, which was centered on
C3 with six neighbor electrodes, and a frontal ROI, which was centered on the electrode between Fz and F3 and its six neighbors (Figure 1(c)).

Afterwards, trials were averaged across sets to determine time and group differences, as well as across all trials to assess time differences in the two groups. All the analyses have been implemented using the FieldTrip toolbox for Matlab [41].

2.4. Statistical Analysis. To quantify the changes of EEG (ERD and ERS magnitude and peak latency) and kinematic measures (reaction time, peak velocity, hand-path area, and total movement time) across sets, we performed repeated measure multivariate ANOVAs (MANOVA) with Group (younger, older) as between-subject effect and practice (15 sets) and parameters and ROI (left and front, only for the EEG analysis) as within-subject effects. We also used univariate mixed model ANOVA for EEG parameters for each ROI (including beta modulation depth) and for kinematic measurements with practice (15 sets) as within-subject effect. All the results had been Greenhouse-Geisser corrected since the assumption of sphericity was violated (Mauchly's test). Pearson coefficients were used to explore significant correlations between kinematic and EEG peak latency parameters. 


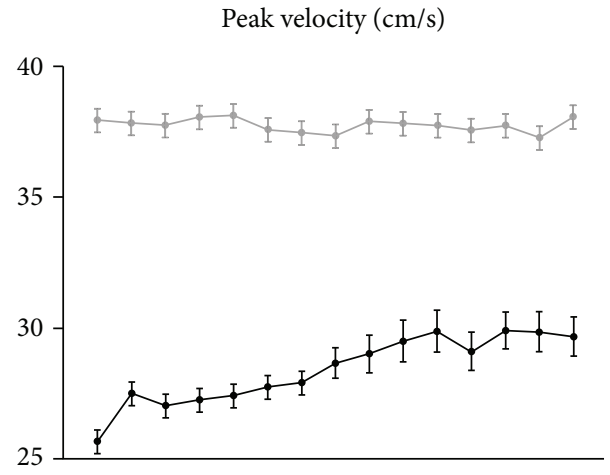

(a)

Total movement time (ms)

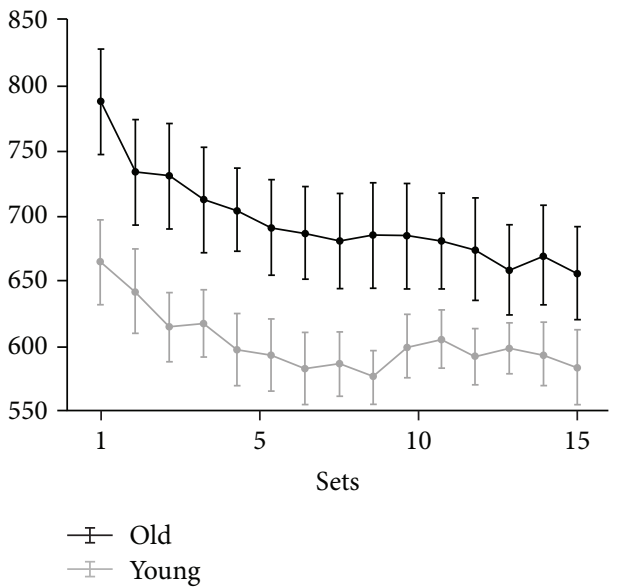

(c)

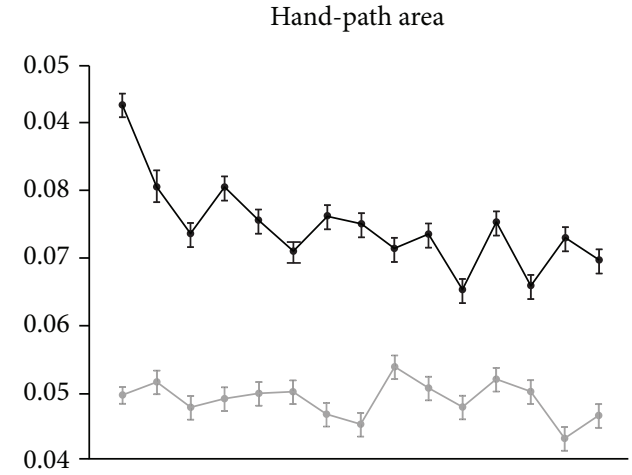

(b)

Reaction time (ms)

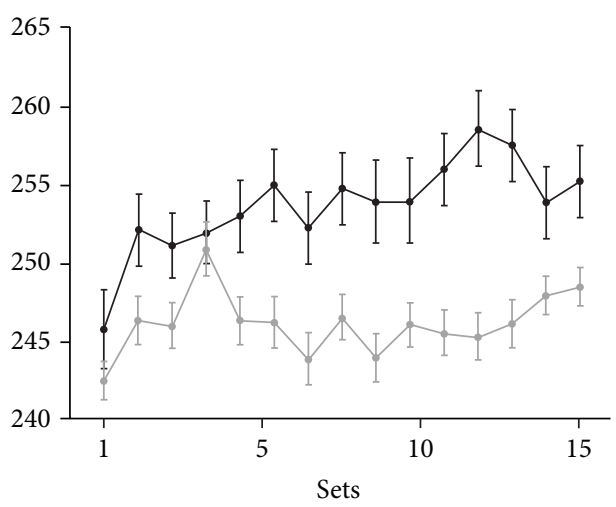

(d)

FIGURE 2: Average of kinematic measures of each set (56 movements each) for the younger (grey lines and dots) and older (black lines and dots) groups. The vertical bars represent standard errors of the mean.

Normality was tested with the Lilliefors test. We used twotailed paired $t$-tests to determine a significant group difference for both ERD and ERS peak latency. Results were considered significant with a $p$ value $<0.05$. All statistical analyses were conducted using SPSS v25 and Matlab 2017b.

\section{Results and Discussion}

3.1. Motor Performance Differs in Younger and Older Subjects. All participants completed the session without any difficulty. In general, movements were mostly straight with bell-shaped velocity profiles in all subjects. The performance measures of the two groups across sets are illustrated in Figure 2. The results of the repeated measure MANOVA revealed an overall effect of practice $\left(F_{(56,1297.47)}=2.86, p<0.001\right)$ and group $\left(F_{(4,21)}=8.80\right.$, $p<0.001)$ and a trend toward significance in the Practice* Group interaction $\left(F_{(56,1297.47)}=1.26, p=0.096\right)$. Results of the univariate tests are reported in Table 1. Specifically, peak velocity values were significantly greater in the younger group without significant changes across sets (Table 1, Figure 2(a)). However, inspection of the data showed some increase across sets, although not significant, only in the older group (Figure 2(a)). In parallel, total movement time was significantly longer in older subjects, with significant decreases across sets in both groups (Table 1, Figure 2(c)). Hand-path area, an inverse measure of spatial accuracy that depends on velocity, was greater in the older participants but decreased in both groups across sets, as shown by a borderline $p$ value (Table 1, Figure 2(b)). Finally, reaction times were rather stable across sets and were slightly longer in the older group, despite mixed model ANOVA did not reveal any main effect or interaction (Table 1, Figure 2(d)). In summary, these results suggest that movements in the older group were slower and spatially less accurate than in the younger group, as confirmed by correlations between the mean values of kinematic parameters and age (peak velocity: $R^{2}=0.43, p<0.001$; hand-path area: $R^{2}=0.28, p=0.006$; total movement time: $R^{2}=0.30$, $p=0.004)$. Additionally, we found a strong correlation between age and the decrease of hand-path area from the first to the last set $\left(R^{2}=0.29, p=0.005\right.$, Supplementary Table 1). Deterioration of motor performance in the elderly has been reported in several publications, involving spatial and temporal characteristics of motor performance. 
TABLE 1: Results of the repeated measure ANOVA, univariate tests of peak velocity, hand-path area, and reaction time comparing groups across practice.

\begin{tabular}{lcccccc}
\hline & \multicolumn{2}{c}{ Group } & \multicolumn{2}{c}{ Practice } & \multicolumn{2}{c}{ GroupXPractice } \\
& $F_{(1,24)}$ & $p$ & $F_{(14,336)}$ & $p$ & $F_{(14,336)}$ & 0.209 \\
\hline Peak velocity & $\mathbf{9 . 5 1}$ & $\mathbf{0 . 0 0 5}$ & 1.32 & 0.277 & 1.63 & 0.095 \\
Hand-path area & $\mathbf{8 . 6 3}$ & $\mathbf{0 . 0 0 7}$ & 2.02 & 0.059 & 1.80 & 0.468 \\
Reaction time & 0.47 & 0.501 & 1.52 & 0.189 & 0.92 & 0.515 \\
Total movement time & $\mathbf{4 . 8 2}$ & $\mathbf{0 . 0 3 8}$ & $\mathbf{1 4 . 9 4}$ & $<\mathbf{0 . 0 0 1}$ & 0.78 & \\
\hline
\end{tabular}

TABLE 2: Results of mixed model univariate ANOVAs for the magnitude of ERD and ERS and beta modulation depth.

\begin{tabular}{lccccccccccccccc}
\hline & \multicolumn{2}{c}{ Group $(\mathrm{G})$} & \multicolumn{2}{c}{ Practice $(\mathrm{P})$} & \multicolumn{2}{c}{$\mathrm{ROI}(\mathrm{R})$} & \multicolumn{2}{c}{$\mathrm{P} * \mathrm{G}$} & \multicolumn{2}{c}{$\mathrm{R} * \mathrm{G}$} & \multicolumn{3}{c}{$\mathrm{P} * \mathrm{R} * \mathrm{R} * \mathrm{G}$} \\
& $F$ & $p$ & $F$ & $p$ & $F$ & $p$ & $F$ & $p$ & $F$ & $p$ & $F$ & $p$ & $F$ & $p$ \\
\hline ERD & 0.07 & 0.788 & $\mathbf{2 . 4 8}$ & $\mathbf{0 . 0 3 5}$ & $\mathbf{6 . 8 8}$ & $\mathbf{0 . 0 1 5}$ & 0.51 & 0.770 & 3.05 & 0.094 & 1.01 & 0.424 & 1.39 & 0.225 \\
ERS & 0.68 & 0.417 & $\mathbf{8 . 9 7}$ & $<\mathbf{0 . 0 0 1}$ & 1.09 & 0.307 & 0.67 & 0.654 & 1.59 & 0.219 & 0.69 & 0.626 & 0.83 & 0.526 \\
$\beta$ Modulation & 0.56 & 0.460 & $\mathbf{9 . 1 3}$ & $\mathbf{< 0 . 0 0 1}$ & 1.44 & 0.241 & 0.67 & 0.657 & 1.78 & 0.195 & 0.71 & 0.614 & 0.78 & 0.563 \\
\hline
\end{tabular}

The causes of this decline are multiple and may involve, singly or in combination, muscular, skeletal, and the central and peripheral nervous systems. During aging, progressive muscle deterioration [42], increased muscle fatigability, and sarcopenia [43-46] may occur with loss of motor units, remodeling of neuromuscular junctions, and eventually with alteration of peripheral and neuromuscular transmissions [47-49]. Besides decreasing muscle strength [50], aging may also impair proprioceptive processing [51], as well as the function of cortical motor regions [48] and the basal ganglia [52]. This can result in mobility problems and an increased risk of falling [53]. Our results showed that, besides being slower, the movements of the older group had greater handpath area values, suggesting a worse interjoint coordination [54-56]. This occurred despite the older groups' movements were slower, and thus, the interaction torques developing during movement should have been easier to counteract, and movements should have had overlapping trajectories. Intact proprioception is necessary for overcoming these forces not only by providing feedback during the movement but also by updating the sensorimotor memories used to program movements through feedforward mechanisms [54-56]. Therefore, even small problems in proprioception information processing, as the ones reported in aging, may produce deficits of intersegmental dynamics, despite low movement velocities, thus resulting in increases of both interjoint timing and hand-path area. Importantly, the older group also showed a decrease of hand-path area across sets with values approaching the range of the younger group in the last sets. This decrease occurred together with an increase of peak velocity, suggesting that some skill learning occurred in the older group. These practice-related improvements also indicate a shift toward the use of feedforward mechanisms and possibly suggest memory formation in this particular aspect of performance [11]. To be noticed, performance of the younger group reached a plateau already in the first set, thus minimizing the significance of the improvements during the last set. This conclusion is supported also by the fact that the values of hand-path area in the older group hardly reached those of the younger subjects (see Figure 2(b)). Therefore, our results suggest that, despite average differences, both groups displayed some learning.

3.2. Beta Modulatory Activity Is Similar in Younger and Older Subjects. We next analyzed the power changes across sets of beta ERD and ERS in the two groups for the left and frontal ROIs. Results are reported in Table 2 and Supplementary Table 2 and illustrated in Figure 3. Multivariate tests with ERD and ERS magnitude did not reveal significant group differences or interactions (Group: $F_{(2,23)}=1.121, p=0.343$; Practice $*$ Group: $F_{(28,672)}=0.548, p=0.973 ; \mathrm{ROI} *$ Group: $F_{(2,23)}=1.47, \quad p=0.251 ; \quad$ Practice $*$ ROI: $\quad F_{(28,670)}=0.899$, $p=0.618 ;$ Practice $*$ ROI $*$ Group: $\left.F_{(28,670)}=1.00, p=0.465\right)$. Nevertheless, we found the main effects of practice and ROI $\left(F_{(28,672)}=4.69, \quad p<0.001 ; \quad F_{(2,23)}=3.71, \quad p=0.040\right.$, respectively). The results of univariate mixed model ANOVAs for ERD and ERS (Table 2) confirmed a significant effect of practice for both measures. They also revealed a difference between ROIs for ERD magnitude (see also: Supplementary Table 2 and Figure 3). Over the frontal ROI, the significant across-set increase extended also to beta ERD (Supplementary Table 2): inspection of the data in Figure 3 suggests that such an effect was more evident, although not significantly so, in the older group. Indeed, some works have shown that older participants need to recruit additional resources in sensorimotor and premotor areas to achieve normal movement execution [57-61]. Thus, the progressive increase of ERD magnitude in older subjects over the frontal ROI may reflect an increased recruitment to improve performance across sets. Univariate mixed model ANOVA for beta modulation depth (Table 2) revealed only a main effect of practice, without any interaction between variables. Finally, as in previous studies $[11,12]$, we found no significant 
ERD magnitude

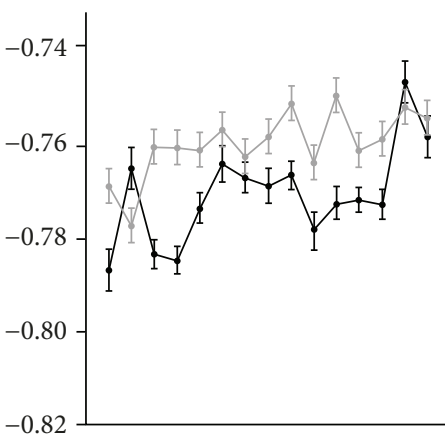

(a)

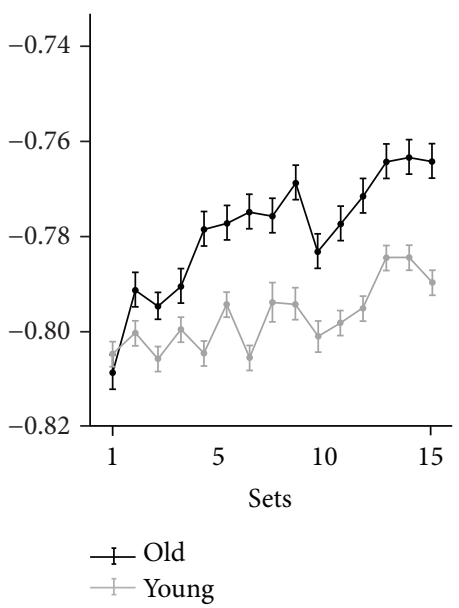

(d)
ERS magnitude

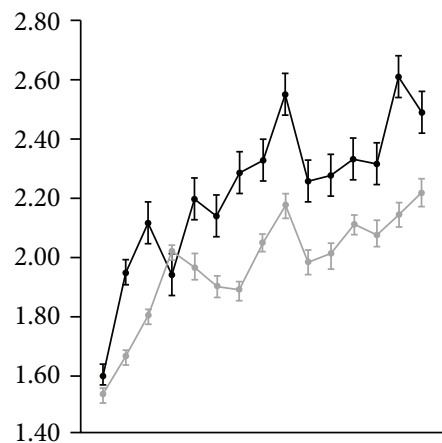

(b)

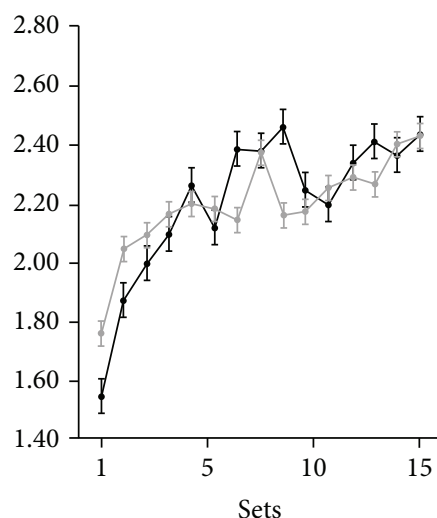

(e)
Beta modulation depth

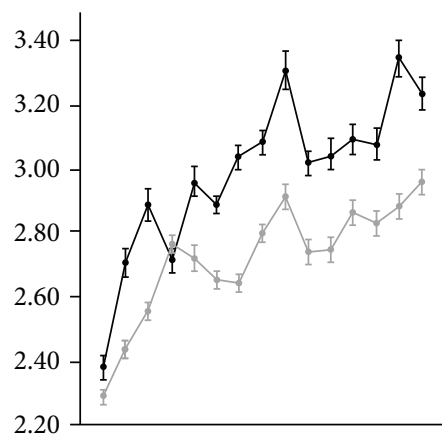

(c)

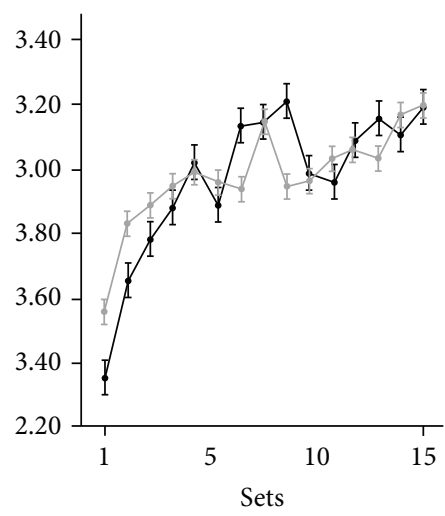

(f)

FIgURE 3: Average of ERD (a, d), ERS (b, e), and beta modulation (c, f) magnitudes for the left (upper row) and frontal (lower row) ROIs for each set in the younger (grey lines and dots) and older (black lines and dots) groups. The vertical bars represent the standard errors of the mean.

correlation between the practice-related changes of ERD, ERS, or beta modulation and the performance changes across sets. Altogether, these results suggest that practicerelated changes of beta modulation in both ROIs are very similar in the two groups. Further analyses on all subjects showed no correlation between the mean values of ERD, ERS, and modulation depth and the subjects' age for both left and frontal ROIs (all: $R^{2}<0.01, p>0.50$ ). Also, correlations between magnitude difference across sets and age did not reveal any direct link between beta modulation and anagraphical age (Supplementary Table 1). These results are in agreement with a study showing no age effect on the mean value of ERD recorded over the left sensorimotor area with a grip task [19], but at odds with a work demonstrating that mean ERD amplitude was greater in older subjects during a motor sequence task [8]. It is conceivable that such discrepant results may originate from differences in task characteristics and sample size. Also, anagraphical age may not be the only and best predictor of changes in cortical function and performance, as it is increasingly more evident that exercise and other factors play important roles in decreasing or accelerating aging processes.
As mentioned earlier, the most novel result is that the increases of beta modulation across sets are similar in the younger and older groups, and notably, this occurs despite important group differences in performance indices (see Figure 2). This result prompts two sets of considerations. First, the magnitude of movement-related beta oscillations does not directly reflect movement characteristics, in line with other studies reporting a lack of correlation between ERD ERS and speed [5, 62], force [63-65], movement type [6], or muscle pattern [7]. Specifically, previous studies found beta oscillatory differences in slow versus fast movements [5]; however, a correlation between EMG burst and ERS latency was detected only for slow movements. Similarly, no direct relationship between movement parameters and ERS, despite an ERS difference between extension-flexion and flexionextension movements, had been found [66]. Also, a recent work from our research group indicated that no link between movement extent and beta modulation magnitude is detected in upper limb reaching movements [67]. Indeed, movementrelated beta oscillations may be related to sensorimotor integration processes associated with movement planning and execution rather than explicitly reflecting the coding of 


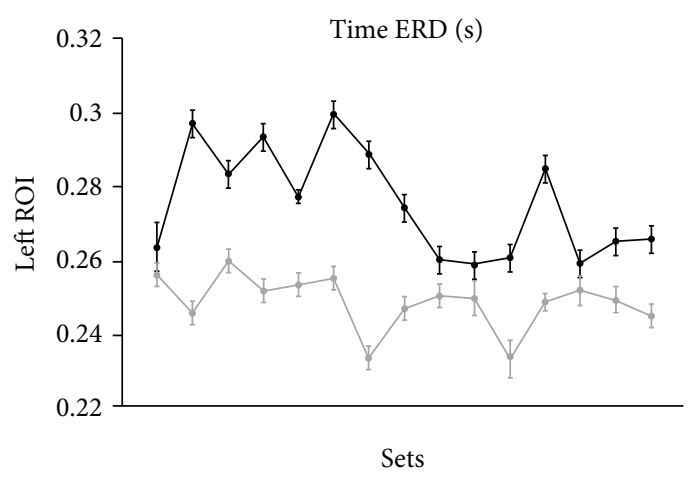

(a)

Time ERD (s)

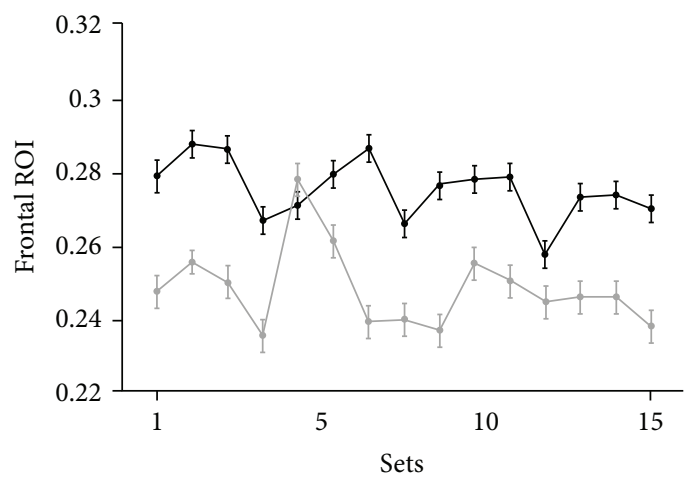

(c)
Time ERS (s)

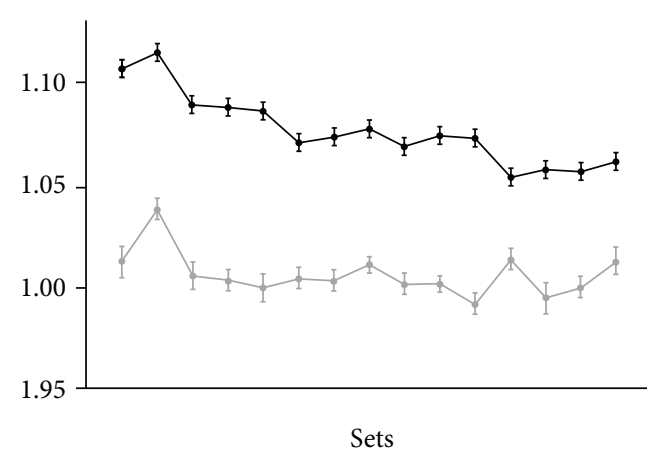

(b)

Time ERS (s)

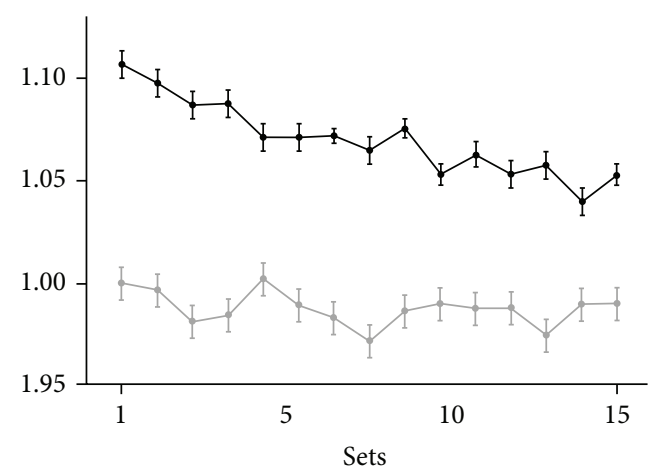

(d)

FIgURE 4: Average peak latencies of ERD ( $a, c)$ and ERS (b, d) for each set in the younger (grey circles and lines) and older (black circles and lines) groups for the left (upper graphs, a and b) and frontal (lower graphs, $\mathrm{c}$ and $\mathrm{d}$ ) ROIs. The vertical bars represent the standard error of the mean.

TABLE 3: Result of repeated measure ANOVAs for ERD and ERS peak latency.

\begin{tabular}{lccccccccccccccc}
\hline & \multicolumn{2}{c}{ Group $(\mathrm{G})$} & \multicolumn{2}{c}{ Practice $(\mathrm{P})$} & \multicolumn{2}{c}{ ROI (R) } & \multicolumn{2}{c}{$\mathrm{P} * \mathrm{G}$} & \multicolumn{2}{c}{$\mathrm{R} * \mathrm{G}$} & \multicolumn{2}{c}{$\mathrm{P} * \mathrm{R}$} & \multicolumn{2}{c}{$\mathrm{P} * \mathrm{R} * \mathrm{G}$} \\
& $F$ & $p$ & $F$ & $p$ & $F$ & $p$ & $F$ & $p$ & $F$ & $p$ & $F$ & $p$ & $F$ & $p$ \\
\hline ERD & $\mathbf{4 . 3 5}$ & $\mathbf{0 . 0 4 8}$ & 1.07 & 0.386 & 0.00 & 0.959 & 0.78 & 0.649 & 0.00 & 0.975 & 1.03 & 0.419 & 0.93 & 0.501 \\
ERS & $\mathbf{1 2 . 4 2}$ & $\mathbf{0 . 0 0 2}$ & $\mathbf{2 . 7 4}$ & $\mathbf{0 . 0 1 5}$ & 3.96 & 0.058 & 1.13 & 0.350 & 1.14 & 0.296 & 0.65 & 0.747 & 0.66 & 0.730 \\
\hline
\end{tabular}

distinct movement features $[68,69]$. The second set of considerations is based on the fact that the continuous performance in our motor tasks should induce constant and regular interplay of sensory and motor regions' activities $[68,69]$, thus providing the bases for use-dependent LTP induction. Improvements of velocity and interjoint coordination indices during the task in the older group indicate a major shift of the performance toward a reinforcement of the feedforward mechanisms, and thus of memory formation. Practice-related beta modulation increase may reflect this phenomenon [11]. If indeed, as also suggested by other evidence $[13,14]$, beta modulation depth increases reflect LTP-like phenomena in the sensorimotor cortex; then, one may speculate that plasticity-related mechanisms in the sensorimotor cortex should not be particularly affected by age. Studies testing the effect of age on the plasticity of the sensorimotor cortex with transcranial magnetic stimulation (TMS) have not shown clear differences between younger and older subjects, and the picture may be further complicated by the influence of hormonal levels on PAS results $[33,70]$ and neural plasticity in general $[71,72]$. Indeed, our results need to be replicated in a larger population, also taking into account the factors other than age that could affect cortical plasticity mechanisms, such as motor and cognitive reserves.

3.3. ERS Peak Latency Occurs Later in Older Adults and Correlates with Total Movement Time. We finally focused on the peak latency of ERD and ERS peaks and determined whether they changed across sets and groups. Indeed, inspection of the data suggests that ERS peak latency was higher in the older but decreased with practice in both groups (Figure 4). Statistical analyses (Table 3, Supplementary Table 3) showed a significant group difference $\left(F_{(2,23)}=7.93, p=0.002\right)$ and a significant effect of practice 
Left ROI

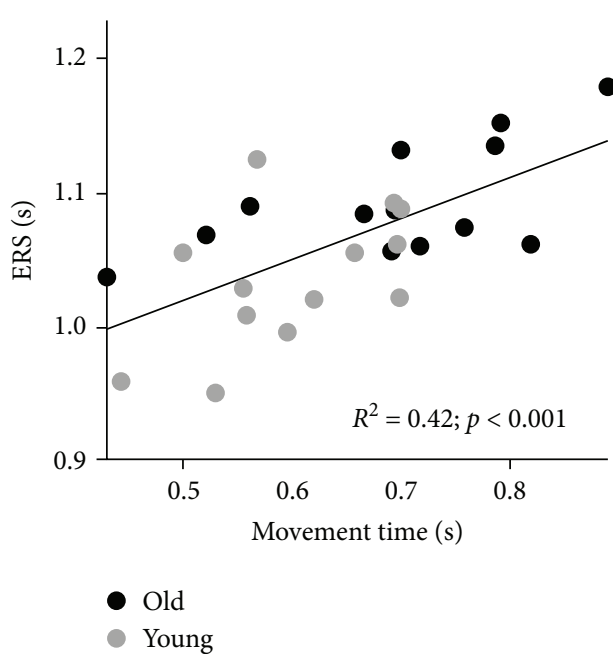

(a)
Frontal ROI

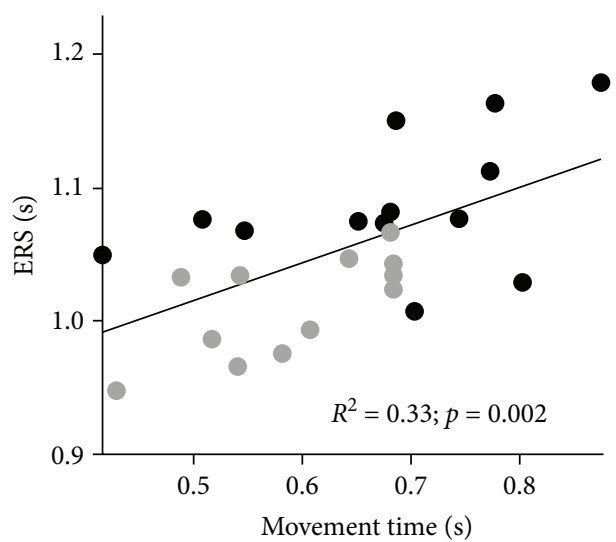

(b)

FIGURE 5: Correlations of total movement time with ERS peak latency in the left (a) and frontal (b) ROIs for younger (gray points) and older (black points) subjects combined.

$\left(F_{(28,670)}=1.75, \quad p=0.010\right)$. However, we found no significant effect of ROI $\left(F_{(2,23)}=2.30, p=0.123\right)$ and interactions $\quad\left(\mathrm{ROI} *\right.$ Group: $\quad F_{(2,23)}=0.634, \quad p=0.540$; Practice $*$ Group: $\quad F_{(28,670)}=0.95, \quad p=0.535$; Practice $*$ ROI: $F_{(28,670)}=0.84, \quad p=0.705 ; \quad$ and Practice $*$ ROI $*$ Group: $\left.F_{(28,670)}=0.80, \quad p=0.766\right)$. Importantly, the temporal occurrence of ERS peak was linked to total movement time in both the left and the frontal ROIs $\left(R^{2}=0.42, p<0.0001\right.$; $R^{2}=0.33, p=0.002$, respectively; Figure 5). However, ERS peak latency did not correlate with other kinematic parameters and with either ERS amplitude or beta modulation depth in both the left and the frontal ROI $\left(R^{2}<0.08, p>0.16\right)$. Altogether, these results show no effect of aging on ERS and ERD peak latency but only a strong dependence of ERS peak latency on movement duration. This is further supported by the lack of significant correlation between changes in peak latency across sets and age (Supplementary Table 1).

Only a few studies have focused on the ERS peak latency or its duration. It is generally accepted that ERS occurs 300-1000 ms after movement ends and lasts several seconds [2, 5, 63, 73-75]. Indeed, the present study with fast reaching movements at a pace of $1.5 \mathrm{~s}$ in a choice reaction time task showed that, on average, the peak latency of peak ERS is highly correlated with the total movement time and that it occurs from 300 to $400 \mathrm{~ms}$ from the end of the out-and-back movement. This observation is in agreement with the idea that ERS peak coincides with a deactivated state of the motor cortex and thus to a reduced excitability of the neuronal populations [76]. The peak latency characteristics of ERS are linked to the type of task and the movement duration. In tasks with isometric wrist contractions, ERS occurrence is related to the rate of force development but not the force output $[63,64]$.
During a task with repetitive movements, ERS occurs earlier than in a task with discrete finger movements [65]. Another work demonstrated that ERS lasts longer after withholding of real foot movements compared to imagined foot movements [77], with the faster movements showing earlier ERS peak occurrence.

\section{Conclusions}

The main result of this study is that, despite being slower and less accurate, the reaching movements of older subjects are associated with beta oscillatory activity that is no different from that accompanying the faster and more precise performance of younger subjects. Importantly, in both groups, the magnitude of beta modulation depth increases to the same degree during practice in both the left and the frontal ROIs. To address the discrepancy between performance and EEG, the results of this study need to be replicated in a larger population and also to take into account the factors other than anagraphical age.

\section{Data Availability}

Data that support the findings of this study are available from the corresponding authors upon reasonable request.

\section{Conflicts of Interest}

The authors declare no competing interests.

\section{Acknowledgments}

All the kinematic data were collected with MotorTaskManager software (designed by E.T.T. Srl, Genova Italy). We would like to thank Maura Casadio, Gabriele Arnulfo, and Andrea Canessa for their insights during data analyses and 
also Giorgia Marchesi, Jing Lin, Shaina George, Francesco Della Gatta, Adhvik Kanagala, and Giulia Aurora Albanese for their help during data acquisition and preprocessing. This work was supported by NIH P01 NS083514 (MFG).

\section{Supplementary Materials}

Supplementary Table 1: correlations between Behavioral parameters and age. Supplementary Table 2: results of the Mixed Model ANOVA for ERD, ERS, and beta modulation comparing groups across practice in the two ROIs. Supplementary Table 3: results of the Mixed Model ANOVA for ERD, ERS, and beta modulation peak latency. (Supplementary Materials)

\section{References}

[1] G. Pfurtscheller and A. Aranibar, "Event-related cortical desynchronization detected by power measurements of scalp EEG," Electroencephalography and Clinical Neurophysiology, vol. 42, no. 6, pp. 817-826, 1977.

[2] G. Pfurtscheller, A. Stancak Jr, and C. Neuper, "Event-related synchronization (ERS) in the alpha band-an electrophysiological correlate of cortical idling: a review," International Journal of Psychophysiology, vol. 24, no. 1-2, pp. 39-46, 1996.

[3] S. Rossi, F. Tecchio, P. Pasqualetti et al., "Somatosensory processing during movement observation in humans," Clinical Neurophysiology, vol. 113, no. 1, pp. 16-24, 2002.

[4] A. M. Cebolla and G. Cheron, "Sensorimotor and cognitive involvement of the beta-gamma oscillation in the frontal N30 component of somatosensory evoked potentials," Neuropsychologia, vol. 79, Part B, pp. 215-222, 2015.

[5] A. Stancák Jr and G. Pfurtscheller, "Desynchronization and recovery of $\beta$ rhythms during brisk and slow self-paced finger movements in man," Neuroscience Letters, vol. 196, no. 1-2, pp. 21-24, 1995.

[6] B. E. Kilavik, M. Zaepffel, A. Brovelli, W. A. MacKay, and A. Riehle, "The ups and downs of beta oscillations in sensorimotor cortex," Experimental Neurology, vol. 245, pp. 15-26, 2013.

[7] R. Salmelin, N. Forss, J. Knuutila, and R. Hari, "Bilateral activation of the human somatomotor cortex by distal hand movements," Electroencephalography and Clinical Neurophysiology, vol. 95, no. 6, pp. 444-452, 1995.

[8] E. Heinrichs-Graham, T. J. McDermott, M. S. Mills et al., "The lifespan trajectory of neural oscillatory activity in the motor system," Developmental Cognitive Neuroscience, vol. 30, pp. 159-168, 2018.

[9] W. Gaetz, M. Macdonald, D. Cheyne, and O. C. Snead, "Neuromagnetic imaging of movement-related cortical oscillations in children and adults: age predicts post-movement beta rebound," NeuroImage, vol. 51, no. 2, pp. 792-807, 2010.

[10] J. Dushanova, D. Philipova, and G. Nikolova, "Beta and gamma frequency-range abnormalities in parkinsonian patients under cognitive sensorimotor task," Journal of the Neurological Sciences, vol. 293, no. 1-2, pp. 51-58, 2010.

[11] A. B. Nelson, C. Moisello, J. Lin et al., "Beta oscillatory changes and retention of motor skills during practice in healthy subjects and in patients with Parkinson's disease," Frontiers in Human Neuroscience, vol. 11, 2017.
[12] C. Moisello, D. Blanco, J. Lin et al., "Practice changes beta power at rest and its modulation during movement in healthy subjects but not in patients with Parkinson's disease," Brain and Behavior, vol. 5, no. 10, article e00374, 2015.

[13] C. J. McAllister, K. C. Rönnqvist, I. M. Stanford, G. L. Woodhall, P. L. Furlong, and S. D. Hall, "Oscillatory beta activity mediates neuroplastic effects of motor cortex stimulation in humans," Journal of Neuroscience, vol. 33, no. 18, pp. 79197927, 2013.

[14] S. D. Hall, G. R. Barnes, P. L. Furlong, S. Seri, and A. Hillebrand, "Neuronal network pharmacodynamics of GABAergic modulation in the human cortex determined using pharmaco-magnetoencephalography," Human Brain Mapping, vol. 31, no. 4, pp. 581-594, 2010.

[15] S. D. Hall, I. M. Stanford, N. Yamawaki et al., "The role of GABAergic modulation in motor function related neuronal network activity," NeuroImage, vol. 56, no. 3, pp. 1506-1510, 2011.

[16] O. Jensen, P. Goel, N. Kopell, M. Pohja, R. Hari, and B. Ermentrout, "On the human sensorimotor-cortex beta rhythm: sources and modeling," NeuroImage, vol. 26, no. 2, pp. 347-355, 2005.

[17] S. D. Muthukumaraswamy, J. F. M. Myers, S. J. Wilson et al., "The effects of elevated endogenous GABA levels on movement-related network oscillations," NeuroImage, vol. 66, pp. 36-41, 2013.

[18] A. K. Roopun, S. J. Middleton, M. O. Cunningham et al., "A beta2-frequency $(20-30 \mathrm{~Hz})$ oscillation in nonsynaptic networks of somatosensory cortex," Proceedings of the National Academy of Sciences of the United States of America, vol. 103, no. 42, pp. 15646-15650, 2006.

[19] H. E. Rossiter, E. M. Davis, E. V. Clark, M.-H. Boudrias, and N. S. Ward, "Beta oscillations reflect changes in motor cortex inhibition in healthy ageing," NeuroImage, vol. 91, no. 100, pp. 360-365, 2014.

[20] N. Yamawaki, I. M. Stanford, S. D. Hall, and G. L. Woodhall, "Pharmacologically induced and stimulus evoked rhythmic neuronal oscillatory activity in the primary motor cortex in vitro," Neuroscience, vol. 151, no. 2, pp. 386-395, 2008.

[21] Y.-F. Hsu, K. K. Liao, P. L. Lee et al., "Intermittent theta burst stimulation over primary motor cortex enhances movementrelated beta synchronisation," Clinical Neurophysiology, vol. 122, no. 11, pp. 2260-2267, 2011.

[22] N. A. Noh, G. Fuggetta, P. Manganotti, and A. Fiaschi, "Long lasting modulation of cortical oscillations after continuous theta burst transcranial magnetic stimulation," PLoS One, vol. 7, no. 4, article e35080, 2012.

[23] M. Cassidy, P. Mazzone, A. Oliviero et al., "Movement-related changes in synchronization in the human basal ganglia," Brain, vol. 125, no. 6, pp. 1235-1246, 2002.

[24] R. Levy, P. Ashby, W. D. Hutchison, A. E. Lang, A. M. Lozano, and J. O. Dostrovsky, "Dependence of subthalamic nucleus oscillations on movement and dopamine in Parkinson's disease," Brain, vol. 125, no. 6, pp. 1196-1209, 2002.

[25] A. A. Kühn, T. Trottenberg, A. Kivi, A. Kupsch, G.H. Schneider, and P. Brown, "The relationship between local field potential and neuronal discharge in the subthalamic nucleus of patients with Parkinson's disease," Experimental Neurology, vol. 194, no. 1, pp. 212-220, 2005. 
[26] P. Bedard and J. N. Sanes, "Basal ganglia-dependent processes in recalling learned visual-motor adaptations," Experimental Brain Research, vol. 209, no. 3, pp. 385-393, 2011.

[27] A. Kishore, T. Joseph, B. Velayudhan, T. Popa, and S. Meunier, "Early, severe and bilateral loss of LTP and LTD-like plasticity in motor cortex (M1) in de novo Parkinson's disease," Clinical Neurophysiology, vol. 123, no. 4, pp. 822-828, 2012.

[28] F. Morgante, A. J. Espay, C. Gunraj, A. E. Lang, and R. Chen, "Motor cortex plasticity in Parkinson's disease and levodopainduced dyskinesias," Brain, vol. 129, no. 4, pp. 1059-1069, 2006.

[29] C. Moisello, D. Blanco, C. Fontanesi et al., "TMS enhances retention of a motor skill in Parkinson's disease," Brain Stimulation, vol. 8, no. 2, pp. 224-230, 2015.

[30] L. Marinelli, D. Crupi, A. di Rocco et al., "Learning and consolidation of visuo-motor adaptation in Parkinson's disease," Parkinsonism \& Related Disorders, vol. 15, no. 1, pp. 6-11, 2009.

[31] Y. Ueki, T. Mima, M. Ali Kotb et al., "Altered plasticity of the human motor cortex in Parkinson's disease," Annals of Neurology, vol. 59, no. 1, pp. 60-71, 2006.

[32] S. N. Burke and C. A. Barnes, "Neural plasticity in the ageing brain," Nature Reviews Neuroscience, vol. 7, no. 1, pp. 30-40, 2006.

[33] F. Tecchio, F. Zappasodi, P. Pasqualetti et al., "Age dependence of primary motor cortex plasticity induced by paired associative stimulation," Clinical Neurophysiology, vol. 119, no. 3, pp. 675-682, 2008.

[34] R. Polimanti, I. Simonelli, F. Zappasodi et al., "Biological factors and age-dependence of primary motor cortex experimental plasticity," Neurological Sciences, vol. 37, no. 2, pp. 211-218, 2016.

[35] J. F. M. Müller-Dahlhaus, Y. Orekhov, Y. Liu, and U. Ziemann, "Interindividual variability and age-dependency of motor cortical plasticity induced by paired associative stimulation," Experimental Brain Research, vol. 187, no. 3, pp. 467-475, 2008.

[36] R. C. Oldfield, "The assessment and analysis of handedness: the Edinburgh inventory," Neuropsychologia, vol. 9, no. 1, pp. 97-113, 1971.

[37] M.-F. Ghilardi, C. Ghez, V. Dhawan et al., "Patterns of regional brain activation associated with different forms of motor learning," Brain Research, vol. 871, no. 1, pp. 127-145, 2000.

[38] C. Moisello, D. Crupi, E. Tunik et al., "The serial reaction time task revisited: a study on motor sequence learning with an arm-reaching task," Experimental Brain Research, vol. 194, no. 1, pp. 143-155, 2009.

[39] A. Delorme and S. Makeig, "EEGLAB: an open source toolbox for analysis of single-trial EEG dynamics including independent component analysis," Journal of Neuroscience Methods, vol. 134, no. 1, pp. 9-21, 2004.

[40] T.-P. Jung, S. Makeig, C. Humphries et al., "Removing electroencephalographic artifacts by blind source separation," Psychophysiology, vol. 37, no. 2, pp. 163-178, 2000.

[41] R. Oostenveld, P. Fries, E. Maris, and J.-M. Schoffelen, "FieldTrip: open source software for advanced analysis of MEG, EEG, and invasive electrophysiological data," Computational Intelligence and Neuroscience, vol. 2011, Article ID 156869, 9 pages, 2011.
[42] S. K. Hunter, H. M. Pereira, and K. G. Keenan, "The aging neuromuscular system and motor performance," Journal of Applied Physiology, vol. 121, no. 4, pp. 982-995, 2016.

[43] J. A. Kent-Braun, D. M. Callahan, J. L. Fay, S. A. Foulis, and J. P. Buonaccorsi, "Muscle weakness, fatigue, and torque variability: effects of age and mobility status," Muscle \& Nerve, vol. 49, no. 2, pp. 209-217, 2014.

[44] C. J. McNeil and C. L. Rice, "Fatigability is increased with age during velocity-dependent contractions of the dorsiflexors," The Journals of Gerontology Series A: Biological Sciences and Medical Sciences, vol. 62, no. 6, pp. 624-629, 2007.

[45] E. J. Metter, N. Lynch, R. Conwit, R. Lindle, J. Tobin, and B. Hurley, "Muscle quality and age: cross-sectional and longitudinal comparisons," The Journals of Gerontology Series A: Biological Sciences and Medical Sciences, vol. 54, no. 5, pp. B207-B218, 1999.

[46] I. S. Raj, S. R. Bird, and A. J. Shield, "Aging and the forcevelocity relationship of muscles," Experimental Gerontology, vol. 45, no. 2, pp. 81-90, 2010.

[47] M. J. Campbell, A. J. McComas, and F. Petito, "Physiological changes in ageing muscles," Journal of Neurology, Neurosurgery \& Psychiatry, vol. 36, no. 2, pp. 174-182, 1973.

[48] R. D. Seidler, J. A. Bernard, T. B. Burutolu et al., "Motor control and aging: links to age-related brain structural, functional, and biochemical effects," Neuroscience \& Biobehavioral Reviews, vol. 34, no. 5, pp. 721-733, 2010.

[49] R. T. Hepple and C. L. Rice, "Innervation and neuromuscular control in ageing skeletal muscle," The Journal of Physiology, vol. 594, no. 8, pp. 1965-1978, 2016.

[50] M. C. Perry, S. F. Carville, I. C. H. Smith, O. M. Rutherford, and D. J. Newham, "Strength, power output and symmetry of leg muscles: effect of age and history of falling," European Journal of Applied Physiology, vol. 100, no. 5, pp. 553-561, 2007.

[51] H. B. Skinner, R. L. Barrack, and S. D. Cook, "Age-related decline in proprioception," Clinical Orthopaedics and Related Research, vol. 184, pp. 208-211, 1984.

[52] N. Raz, K. M. Rodrigue, K. M. Kennedy, D. Head, F. GunningDixon, and J. D. Acker, "Differential aging of the human striatum: longitudinal evidence," American Journal of Neuroradiology, vol. 24, no. 9, pp. 1849-1856, 2003.

[53] J. Verghese, A. LeValley, C. B. Hall, M. J. Katz, A. F. Ambrose, and R. B. Lipton, "Epidemiology of gait disorders in community-residing older adults," Journal of the American Geriatrics Society, vol. 54, no. 2, pp. 255-261, 2006.

[54] R. L. Sainburg, M. F. Ghilardi, H. Poizner, and C. Ghez, "Control of limb dynamics in normal subjects and patients without proprioception," Journal of Neurophysiology, vol. 73, no. 2, pp. 820-835, 1995.

[55] R. Huber, M. F. Ghilardi, M. Massimini et al., "Arm immobilization causes cortical plastic changes and locally decreases sleep slow wave activity," Nature Neuroscience, vol. 9, no. 9, pp. 1169-1176, 2006.

[56] C. Moisello, M. Bove, R. Huber et al., "Short-term limb immobilization affects motor performance," Journal of Motor Behavior, vol. 40, no. 2, pp. 165-176, 2008.

[57] A. Sailer, J. Dichgans, and C. Gerloff, "The influence of normal aging on the cortical processing of a simple motor task," Neurology, vol. 55, no. 7, pp. 979-985, 2000. 
[58] S. Heuninckx, N. Wenderoth, F. Debaere, R. Peeters, and S. P. Swinnen, "Neural basis of aging: the penetration of cognition into action control," Journal of Neuroscience, vol. 25, no. 29, pp. 6787-6796, 2005.

[59] S. Heuninckx, N. Wenderoth, and S. P. Swinnen, "Systems neuroplasticity in the aging brain: recruiting additional neural resources for successful motor performance in elderly persons," Journal of Neuroscience, vol. 28, no. 1, pp. 91-99, 2008.

[60] S. P. Swinnen, S. Heuninckx, A. Van Impe, D. J. Goble, J. P. Coxon, and N. Wenderoth, "Aging and movement control: the neural basis of age-related compensatory recruitment," Motor Control, vol. 17, pp. 383-413, 2010.

[61] A. Vallesi, A. R. McIntosh, and D. T. Stuss, "Overrecruitment in the aging brain as a function of task demands: evidence for a compensatory view," Journal of Cognitive Neuroscience, vol. 23, no. 4, pp. 801-815, 2011.

[62] A. Stancák Jr and G. Pfurtscheller, "Event-related desynchronisation of central beta-rhythms during brisk and slow selfpaced finger movements of dominant and nondominant hand," Cognitive Brain Research, vol. 4, no. 3, pp. 171-183, 1996.

[63] A. Fry, K. J. Mullinger, G. C. O'Neill et al., "Modulation of post-movement beta rebound by contraction force and rate of force development," Human Brain Mapping, vol. 37, no. 7, pp. 2493-2511, 2016.

[64] S. Cremoux, J. Tallet, E. Berton, F. Dal Maso, and D. Amarantini, "Motor-related cortical activity after cervical spinal cord injury: multifaceted EEG analysis of isometric elbow flexion contractions," Brain Research, vol. 1533, pp. 44-51, 2013.

[65] Y.-Z. Wu, D. M. Niddam, C. C. Chen et al., "Effects of cognitive demands on postmovement motor cortical deactivation," NeuroReport, vol. 17, no. 4, pp. 371-375, 2006.

[66] A. Stančák Jr, “The electroencephalographic $\beta$ synchronization following extension and flexion finger movements in humans," Neuroscience Letters, vol. 284, no. 1-2, pp. 41-44, 2000.

[67] E. Tatti, S. Ricci, R. Mehraram et al., "Beta modulation depth is not linked to movement features," Frontiers in Behavioral Neuroscience, vol. 13, p. 49, 2019.

[68] H. Shimazu, R. Kaji, N. Murase et al., "Pre-movement gating of short-latency somatosensory evoked potentials," NeuroReport, vol. 10, no. 12, pp. 2457-2460, 1999.

[69] F. Cassim, W. Szurhaj, H. Sediri et al., "Brief and sustained movements: differences in event-related (de) synchronization (ERD/ERS) patterns," Clinical Neurophysiology, vol. 111, no. 11, pp. 2032-2039, 2000.

[70] G. Fernández, S. Weis, B. Stoffel-Wagner et al., "Menstrual cycle-dependent neural plasticity in the adult human brain is hormone, task, and region specific," The Journal of Neuroscience, vol. 23, no. 9, pp. 3790-3795, 2003.

[71] M. M. Adams and J. H. Morrison, "Estrogen and the aging hippocampal synapse," Cerebral Cortex, vol. 13, no. 12, pp. 1271-1275, 2003.

[72] H. A. Hofmann, "Gonadotropin-releasing hormone signaling in behavioral plasticity," Current Opinion in Neurobiology, vol. 16, no. 3, pp. 343-350, 2006.

[73] G. Pfurtscheller, "Event-related synchronization (ERS): an electrophysiological correlate of cortical areas at rest," Electroencephalography and Clinical Neurophysiology, vol. 83, no. 1, pp. 62-69, 1992.
[74] R. Salmelin and R. Hari, "Spatiotemporal characteristics of sensorimotor neuromagnetic rhythms related to thumb movement," Neuroscience, vol. 60, no. 2, pp. 537-550, 1994.

[75] M. T. Jurkiewicz, W. C. Gaetz, A. C. Bostan, and D. Cheyne, "Post-movement beta rebound is generated in motor cortex: evidence from neuromagnetic recordings," NeuroImage, vol. 32, no. 3, pp. 1281-1289, 2006.

[76] R. Chen, Z. Yaseen, L. G. Cohen, and M. Hallett, "Time course of corticospinal excitability in reaction time and self-paced movements," Annals of Neurology, vol. 44, no. 3, pp. 317325, 1998.

[77] T. Solis-Escalante, G. R. Müller-Putz, G. Pfurtscheller, and C. Neuper, "Cue-induced beta rebound during withholding of overt and covert foot movement," Clinical Neurophysiology, vol. 123, no. 6, pp. 1182-1190, 2012. 


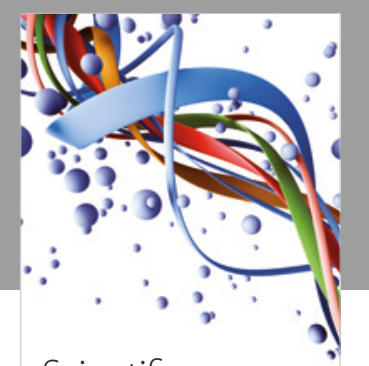

Scientifica
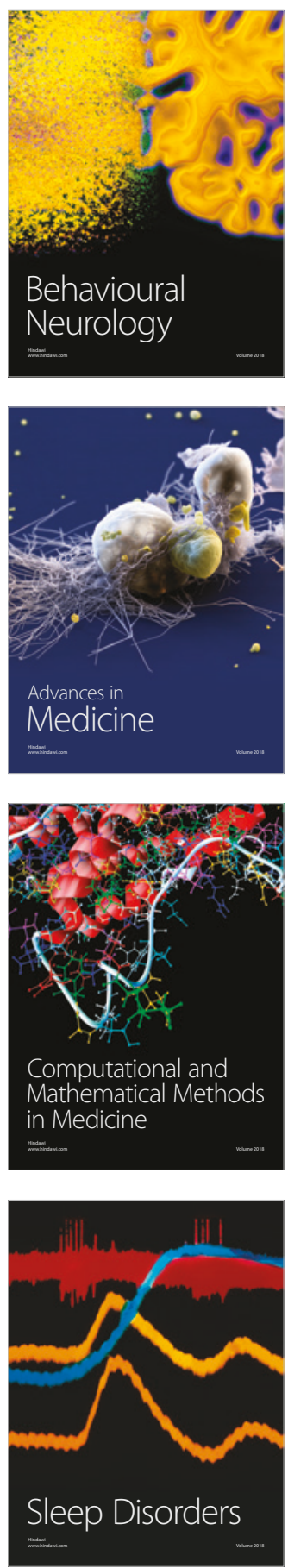

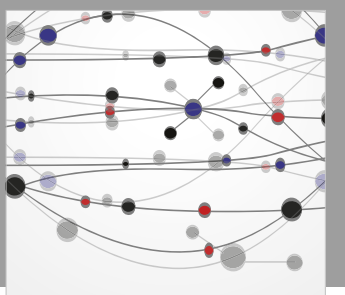

The Scientific World Journal

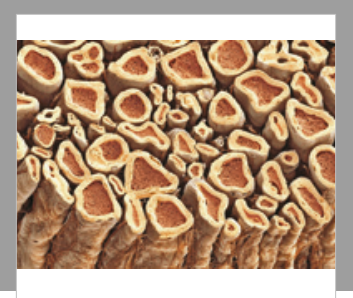

Case Reports in

Neurological Medicine

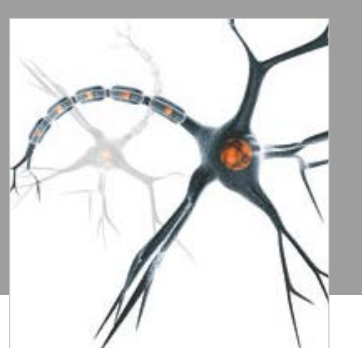

Neural Plasticity

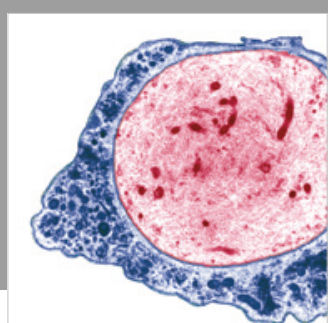

Multiple Sclerosis

International

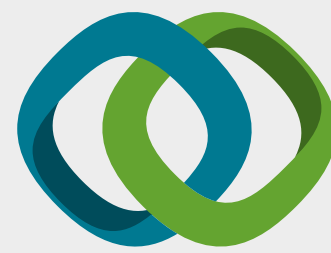

Hindawi

Submit your manuscripts at

www.hindawi.com
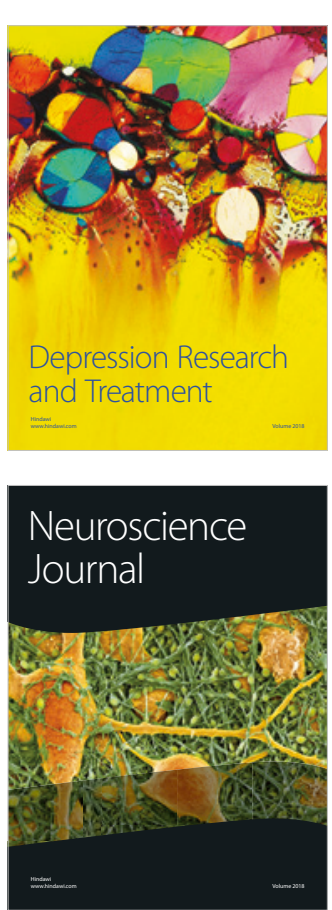

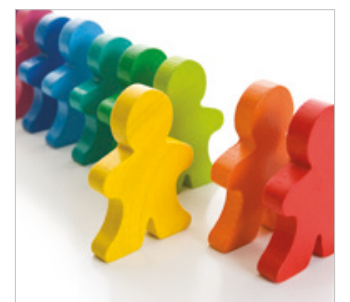

Autism

Research and Treatment
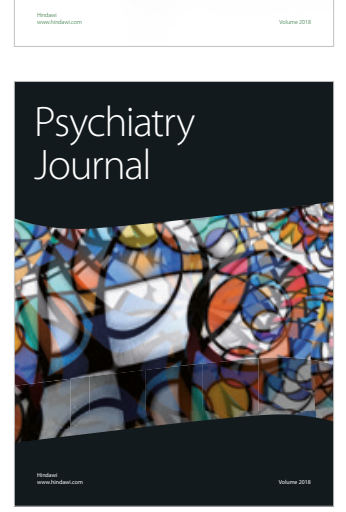
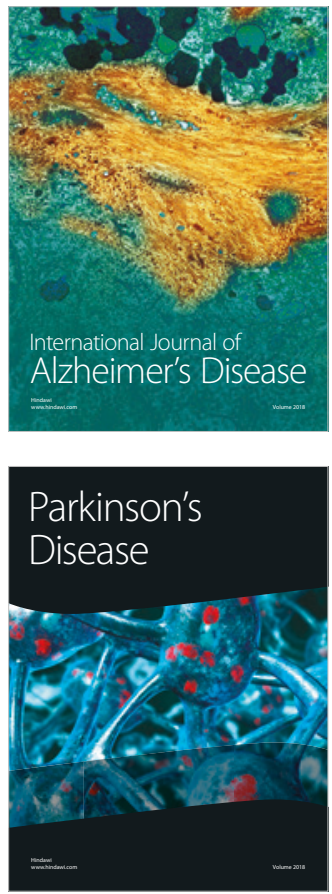
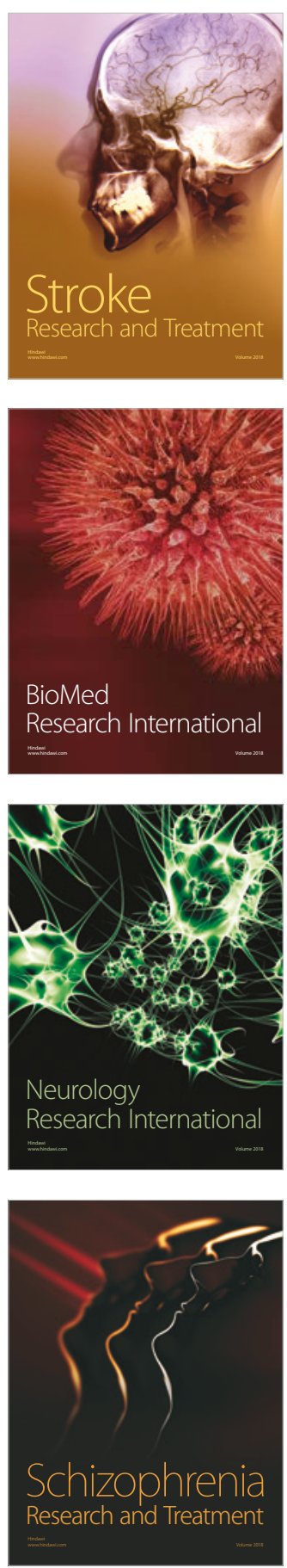